PROGRESS REPORT

for

INFRARED ABSORPTION SPECTROSCOPY AND CHEMICAL KINETICS OF FREE

RADICALS

DE-FG05-85ER 13439

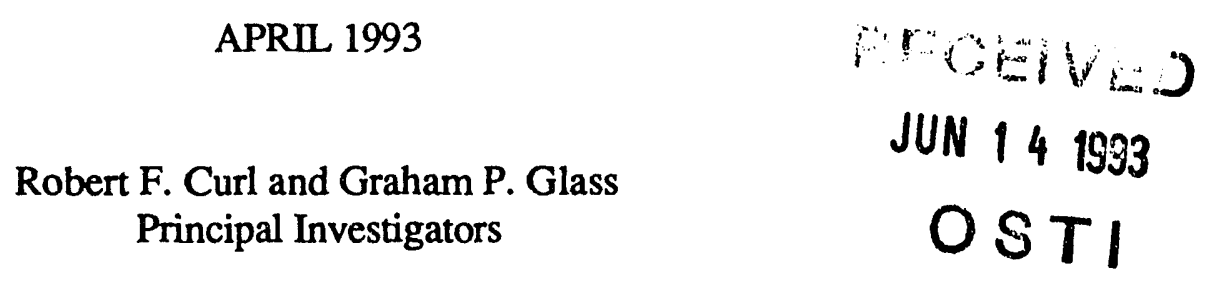

During the last year, three research projects have been essentially completed: a high resolution spectroscopic investigation of $\mathrm{CH}$ stretch of $\mathrm{HCCN}$, measurement of the rate constant of the reaction between ethynyl $\left(\mathrm{C}_{2} \mathrm{H}\right)$ radical and $\mathrm{H}_{2}$ in the temperature region between 295 and $875 \mathrm{~K}$, and measurement of the recombination rate of propargyl $\left(\mathrm{CH}_{2} \mathrm{CCH}\right)$ at room temperature.

\title{
THE $v_{1}$ FUNDAMENTAL OF HCCN
}

The CH stretch fundamental, $v_{1}$, was observed, assigned, and analyzed. HCCN was produced by $193 \mathrm{~nm}$ excimer laser photolysis of dibromoacetonitrile

$$
\mathrm{HBr}_{2} \mathrm{CCN}+\mathrm{h} v(193 \mathrm{~nm}) \rightarrow \mathrm{HCCN}+2 \mathrm{Br}
$$

and the region of the CH stretching fundamental of the ground triplet state near $3250 \mathrm{~cm}^{-1}$ was probed with a tunable color center laser. In addition to the $\mathrm{CH}$ stretching fundamental, several hot bands associated with excitation of the $\mathrm{CH}$ stretch from excited states of the bending vibrations were observed and the two bands associated with the lowest energy bending fundamentals, $v_{1}+v_{5}-v_{5}$ and $v_{1}+v_{4}-v_{4}$, were analyzed. From measurements of the intensity of these hot bands relative to the fundamental, the energy of $v 5$ and $v 4$ have been found to be $187 \pm 20 \mathrm{~cm}^{-1}$ and $383 \pm 20 \mathrm{~cm}^{-1}$ respectively. The value found for $v 5,187 \pm 20$ $\mathrm{cm}^{-1}$, which corresponds to the energy of the lowest excited state involving off-axis motion, is intermediate between that expected for a normal linear molecule and that expected for a bent molecule suggesting a very floppy HCX bending potential characteristic of a quasilinear molecule.

The bending vibrational energy levels of the ground electronic state of $\mathrm{HCCN}$ have been calculated for a range of possible bending potentials by Malmquist et al ${ }^{1}$ who carried out an $a b$ initio study of the triplet ground electronic state of $\mathrm{HCCN}$. As with all other $a b$ initio calculations of the structure of ground state HCCN, they found the equilibrium geometry of the molecule is bent. Because all previous spectroscopic investigations of HCCN found the molecule to be linear, Malmquist $e$ al provided the bending energy levels for a parametrically variable potential function capable of taking the bent $a b$ initio potential all the way to linearity. The bending potential resulting from their parameterization that gives $v 5 \approx 190 \mathrm{~cm}^{-1}$ is depicted above. This potential suggests that the HCC bond angle flops about linearity. 


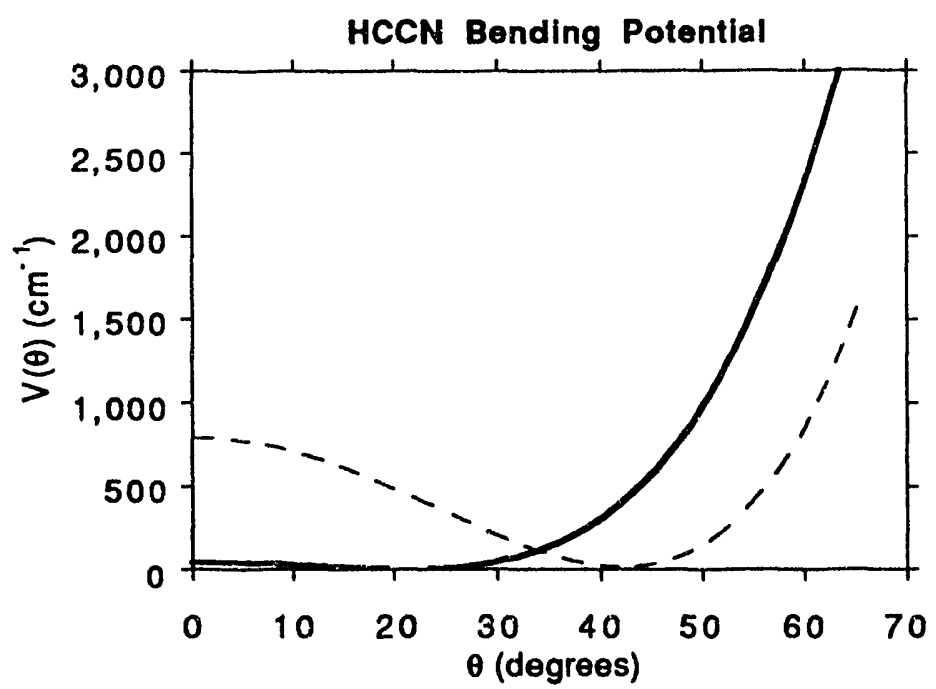

Figure 1. Potential function for the HCC angle agreeing with observed v5 energy. The molecule is linear when $\theta=0$. The dashed curve is the ab initio $(\mathrm{CCl})$ curve of Malmquist $e t$ al.

\section{MEASUREMENT OF THE RATE CONSTANT FOR THE REACTION BETWEEN CCH AND H2 AT ELEVATED TEMPERATURES}

High temperature rate measurements on the reaction between $\mathrm{C}_{2} \mathrm{H}$ and molecular hydrogen:

$$
\mathrm{C}_{2} \mathrm{H}+\mathrm{H}_{2} \rightarrow \mathrm{H}+\mathrm{C}_{2} \mathrm{H}_{2}
$$

are crucial to a critical evaluation of the mechanism of acetylene pyrolysis, 2,3 which, of course, is an essential part of any more general hydrocarbon combustion mechanism. Since $\mathrm{C}_{2} \mathrm{H}$ formation in such systems occurs primarily via the reverse of reaction (2), and since no experimental measurements of reaction (-2) exist, it is usual, when modelling either acetylene pyrolysis or combustion, to estimate the rate of reaction $(-2)$ from the equilibrium constant, $\mathrm{K}_{2}$, and the rate constant, $\mathrm{k}_{2}$, for the forward reaction. Only one direct experimental investigation of the reaction between $\mathrm{C}_{2} \mathrm{H}$ and $\mathrm{H}_{2}$ at temperatures in excess of $300 \mathrm{~K}$ has been published. ${ }^{4}$ This study suffers from two limitations: (1) It covered only a limited temperature range (298-438 K), and (2) only the ratio of $\mathrm{k}_{2}$ to the rate of reaction of $\mathrm{C}_{2} \mathrm{H}$ with acetylene, was measured. The only information concerning the rate of reaction (2) at combustion temperatures, comes from a TST calculation by Harding et al,$^{5}$ which utilized ab initio methods (POL-CI) for determining the properties of the potential energy surface in the saddle point region.

In our work, the rate of the reaction between $\mathrm{C}_{2} \mathrm{H}$ and $\mathrm{H}_{2}$ has been measured over the temperature range $295-855 \mathrm{~K}$. The $\mathrm{C}_{2} \mathrm{H}$ radical was produced by excimer laser photolysis of $\mathrm{C}_{2} \mathrm{H}_{2}$ at $193 \mathrm{~nm}$, and its transient absorption was monitored throughout the reaction by using a tunable infrared color-center laser. The temperature dependence of the rate constant exhibited a non-Arrhenius form that could be well represented by the expression: $k=$ $(9.44 \pm 0.50) \times 10^{-14} \mathrm{~T}^{0.9} \exp (-1003 \pm 40 / \mathrm{T}) \mathrm{cm}^{3}$ molecule $^{-1} \mathrm{~s}^{-1}$. Figure 2 shows a comparison of our data with previous work. 


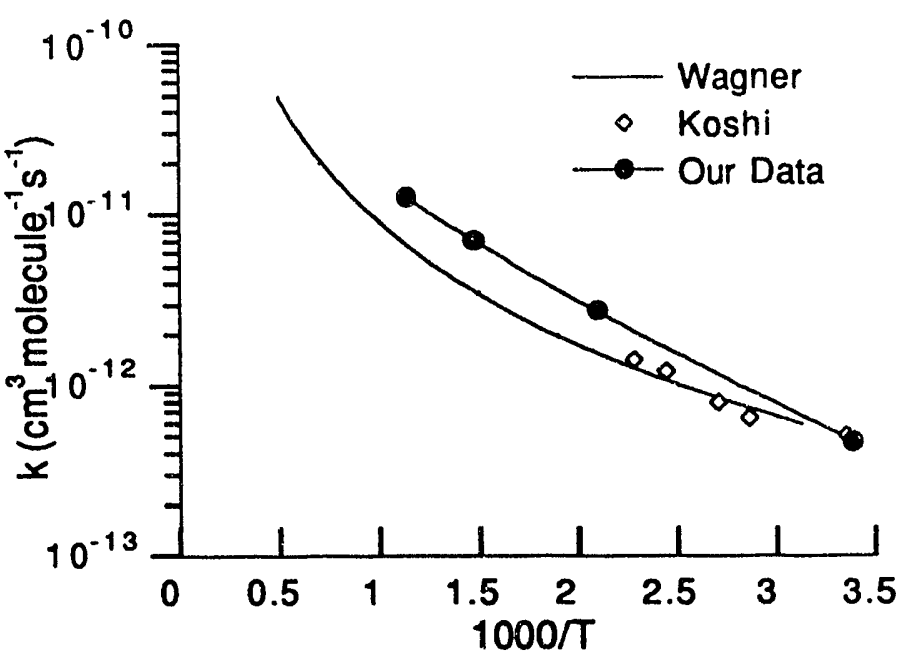

Fig. 2. The rate of the reaction, $\mathrm{C}_{2} \mathrm{H}+\mathrm{H}_{2}$, as a function of temperature.

\section{RECOMBINATION RATE OF PROPARGYL RADICAL}

We reported last year an infrared kinetic spectroscopic investigation of the $\mathrm{CH}$ stretching fundamental of propargyl radical and described in our oral presentation preliminary measurements of the propargyl recombination rate at room temperature. Propargyl is produced by flash photolysis of propargyl bromide or chloride.

$$
\mathrm{CH}_{2} \mathrm{X}-\mathrm{C} \equiv \mathrm{CH}+\mathrm{hv} \rightarrow \mathrm{X}+\mathrm{CH}_{2}-\mathrm{C} \equiv \mathrm{CH}
$$

with $\mathrm{X}=\mathrm{Br}$ or $\mathrm{Cl}$. Another possible photolysis channel may be

$$
\mathrm{CH}_{2} \mathrm{X}-\mathrm{C} \equiv \mathrm{CH}+\mathrm{h} v \rightarrow \mathrm{HX}+\mathrm{CH}-\mathrm{C} \equiv \mathrm{CH}
$$

The time decay of the propargyl signal follows second order kinetics suggesting that propargyl is reacting with itself or another photolyis product. When $\mathrm{X}=\mathrm{Br}$, the $\mathrm{Br}$ atom can be observed with the same apparatus using the magnetic-dipole-allowed fine structure transition of the bromine atom at $3685 \mathrm{~cm}^{-1}$. As the Br absorption cross section is known, the infrared absorption cross-section of propargyl can be determined by comparing its intensity to that of $\mathrm{Br}$ using the stoichiometry of reaction (3). The $\mathrm{Br}$ atom signal exhibits first order decay, which is faster than the propargyl decay under the same conditions. These observations show that propargyl does not react with the precursor $\mathrm{C}_{3} \mathrm{H}_{3} \mathrm{Br}$ nor with $\mathrm{Br}$. When $\mathrm{X}=\mathrm{Cl}$, it is possible to observe transitions of the $\mathrm{HCl}$ vibrational fundamental. Indeed these appear promptly upon photolysis indicating that (4) is actually taking place. However, quantitative measurements establish that the ratio of moles $\mathrm{HCl}$ to moles $\mathrm{C}_{3} \mathrm{H}_{3}$ is $0.14 \pm .02$. Thus (4) is a minor channel when $\mathrm{X}=\mathrm{Cl}$, and the observed second order decay of propargyl must be caused by the reaction of propargyl with itself probably via recombination. These observations permit the determination of this recombination rate by measurement of the decay of the $\mathrm{C}_{3} \mathrm{H}_{3}$ concentration with time after photolysis of propargyl chloride. The resulting rate constant is $1.8(4) \times 10^{-10} \mathrm{~cm}^{3}$ molecule-1 $\mathrm{s}^{-1}$.

\section{DISCLAIMER}

This report was prepared as an account of work sponsored by an agency of the United States Government. Neither the United States Government nor any agency thereof, nor any of their employees, makes any warranty, express or implied, or assumes any legal liability or responsibility for the accuracy, completeness, or usefulness of any information, apparatus, product, or process disclosed, or represents that its use would not infringe privately owned rights. Reference herein to any specific commercial product, process, or service by trade name, trademark, manufacturer, or otherwise does not necessarily constitute or imply its endorsement, recommendation, or favoring by the United States Government or any agency thereof. The views and opinions of authors expressed herein do not necessarily state or reflect those of the United States Government or any agency thereof. 


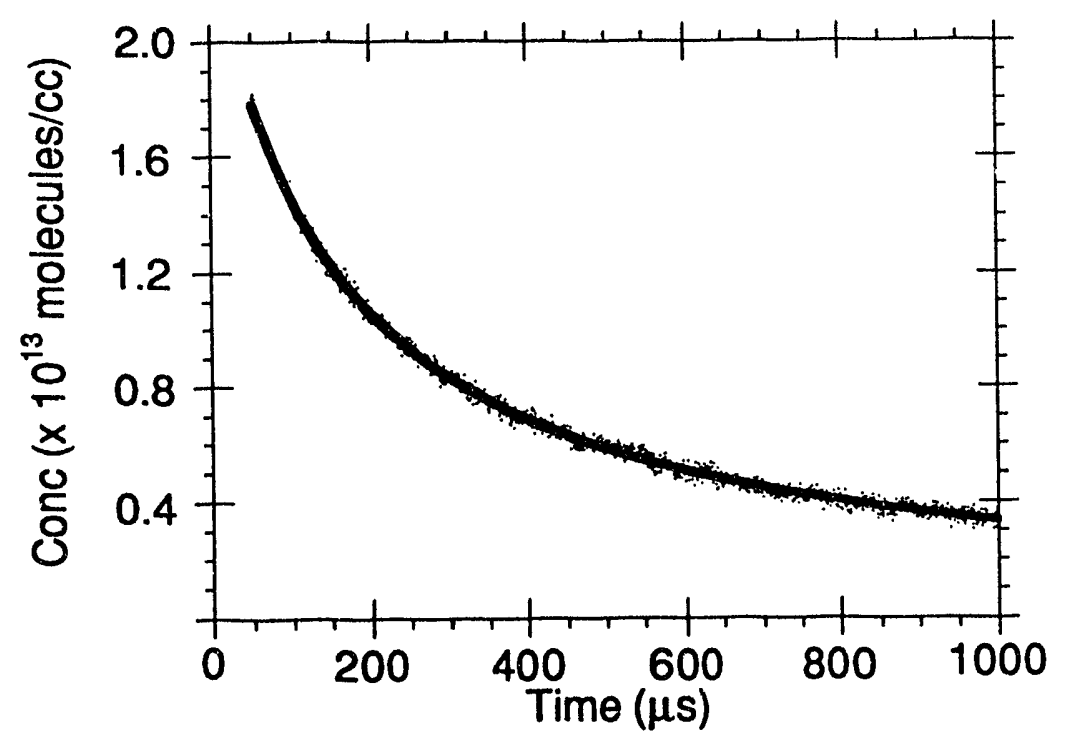

Fig. 3 Time decay of propargyl concentration fitted by second order kinetics expression.

1P. Malmquist, R. Lindh, B. O. Roos, and S. Ross, Theo. Chim. Acta 73 (1988) 155.

2J. H. Kiefer, and W. A. Von Drasek, Int. J. Chem. Kinetics, 22, 747 (1990).

${ }^{3}$ R. D. Kern, K. Xie, H. Chen, and J. H. Kiefer, 23rd Symposium (International) on Combustion (The Combustion Institute, Pittsburgh 1990) p. 69.

${ }^{4}$ M. Koshi, K. Fukuda, K. Kamiya, and H. Matsui, J. Phys. Chem., 96, 9839 (1992).

5L. B. Harding, G. C. Schatz, and R. A. Chiles, J. Chem. Phys., 76, 5172 (1982). 
5

Publications

1. "Acetylene Combustion Reactions: Rate Constant Measurements of $\mathrm{HCCO}$ with $\mathrm{O}_{2}$ and $\mathrm{C}_{2} \mathrm{H}_{2}$," K. K. Murray, K. G. Untried, G. P. Glass, and R. F. Curl, Chem. Phys. Lett. 192, 512-516 (1992)

2. "Rotationally Resolved Spectrum of the $\mathrm{CH}$ Stretch of the Propargyl Radical $\left(\mathrm{H}_{2} \mathrm{CCCH}\right)$," C. L. Morter, C. Domingo, S. K. Farhat, E. Cartwright, R. F. Curl, and G. P. Glass, Chem. Phys. Lett. 195, 316-321 (1992).

3. "The $v_{1}$ fundamental of HCCN: Evidence for quasilinearity", C. L. Morter, S. K. Farhat, and R. F. Curl, Chem. Phys. Lett. (accepted). 

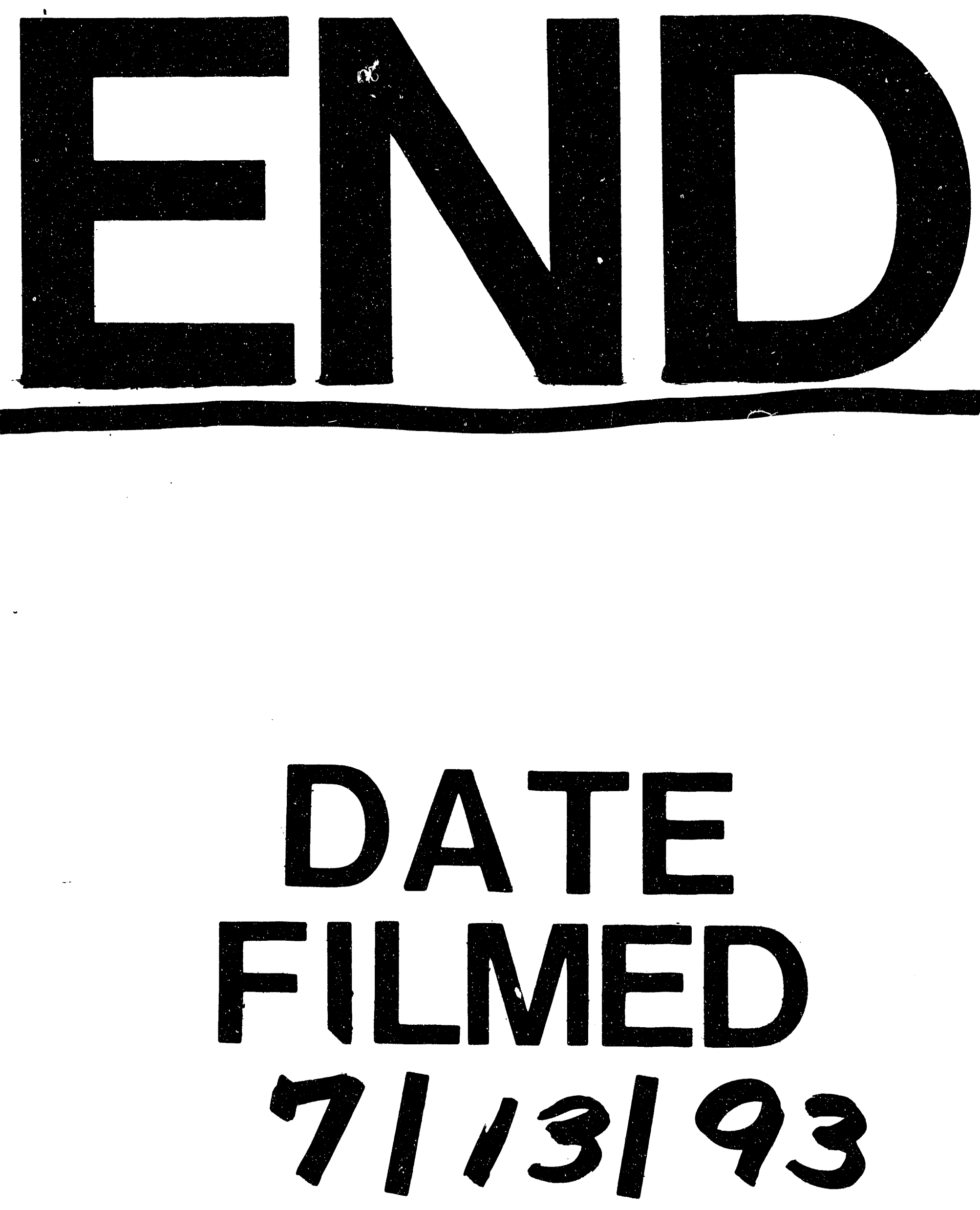
